

\section{Learning ability is a key outcome determinant of GSK-3 inhibition on visuospatial memory in rats}

Zinaida I. Storozheva ${ }^{1,2}$, Marina A. Gruden ${ }^{1}$, Andrey T. Proshin ${ }^{1}$, Robert D. E. Sewell ${ }^{3}$

${ }^{1}$ Federal State Budgetary Scientific Institution, P. K. Anokhin Research Institute of Normal Physiology, 125315, Baltiskaya St., 8, Moscow, Russia.

${ }^{2}$ Serbsky State Scientific Center for Social and Forensic Psychiatry, Kropotkinsky Per. 23, 119034, Moscow, Russian Federation.

${ }^{3}$ Cardiff School of Pharmacy and Pharmaceutical Sciences, Cardiff University, Cardiff, CF10 3NB, U.K.

Short title: Learning ability, GSK-3 inhibition and memory

\section{Corresponding author:}

Robert Sewell, Cardiff School of Pharmacy and Pharmaceutical Sciences, Cardiff University, Cardiff, CF10 3NB, U.K.

Email: sewell@cardiff.ac.uk 


\begin{abstract}
Learning aptitude has never been a focus of visuospatial performance studies particularly on memory consolidation and reconsolidation. The aim was to determine the consequences of learning ability on memory consolidation/reconsolidation following inhibition of glucose synthase kinase-3 (GSK-3) by 4-benzyl-2-methyl-1,2,4-thiadiazolidine-3,5-dione (TDZD-8). The anxiety-like nature of rats was characterized in the elevated plus maze. The rats were then trained for 4 days in the Morris water maze (MWM) and classified as "superior", "intermediate" or "inferior" learners. There were no major differences between superior, intermediate or inferior learners with respect to anxiety which might have influenced learning. After training (day-5), TDZD-8 (2.0 mg/kg) was administered and half the cohort was exposed to a MWM retrieval trial. Ten days later, animals were subjected to repeated MWM learning. TDZD-8 without a retrieval trial impaired subsequent reconsolidation in inferior learners, but enhanced it in superior learners. There was no modification of performance in intermediate learners. In TDZD-8-treated subjects exposed to retrieval, the pattern of outcomes was identical whereby impairment of reconsolidation occurred in inferior learners, enhancement in superior learners but there was no modification of performance in intermediate learners. Thus, learning ability was a key determinant of the qualitative outcome from GSK-3 inhibition on visuospatial memory.
\end{abstract}

Key words: visuospatial memory, learning ability, GSK-3 inhibition, TDZD-8, consolidation/ reconsolidation. 


\section{Introduction}

Cognitive abilities are a universal feature within humans, but rodents need to express their learning abilities in novel environmental contexts in order for them to be evaluated. The diverse learning abilities of laboratory animals are influenced by a common source of variance (Matzel et al., 2003) and these learning aptitudes have been studied using different approaches including pharmacological manipulations (Meijer et al., 2004; Sierksma et al., 2014; Hutchings et al., 2013). In this context, some of the molecular pathways which are important for normal brain function and intracellular signalling involve the enzyme glycogen synthase kinase-3 (GSK-3) (Grimes and Jope, 2001).

The enzyme GSK-3 is abundant in the central nervous system, particularly in the hippocampus (Perez-Costas et al., 2010) and it is implicated in fundamental neuronal functions, such as neurodevelopment (Kim et al., 2009), and neurotransmitter function (Li et al., 2012). It was originally identified as a regulator of glycogen metabolism and later, its significance in protein synthesis, cell proliferation, differentiation, survival and apoptosis was established (Grimes and Jope, 2001). Transmembrane signalling mechanisms are critical for regulating the plasticity of neuronal connections underlying the establishment of long-lasting memory (Chen et al., 2011). The enzyme GSK-3 operates within at least two very different signalling pathways, which include insulin and the Wnt cascade. This enzyme is a downstream target of insulin stimulation and regulates glycogen synthase, the protein translation regulating factor $\mathrm{eIF} 2 \mathrm{~B}$ and the transcription factor C/EBP (Harwood, 2001). In contrast, GSK-3 is also regarded a central element of the Wnt signalling pathway which has been proposed to regulate several developmental processes (Harwood, 2001, Gersten et al., 2014) and long-term information storage in a behavioural-, cellular-, and isoform-specific manner (Tabatadze et al., 2011). In mammals GSK-3 is encoded by two known genes, GSK3 alpha $(G S K 3 A)$ and GSK-3 beta $(G S K 3 B)$ however, two protein isoforms, alpha (GSK-3 $\alpha)$ and beta (GSK-3 $\beta$ ), show a high degree of amino acid homology.

It is noteworthy that inactivation of GSK-3 $\beta$ and the resulting stabilization of free $\beta$-catenin in the Wnt pathway are critical steps in the activation of Wnt target genes. Additionally, it is thought that expression of the Wnt cascade increases protein kinase B (Akt) activity regulating GSK3 in the phosphatidylinositide 3-OH kinase signalling pathway. Activated Akt 
bound to the Axin-GSK3 $\beta$ complex, also phosphorylates GSK3 $\beta$ and increases free $\beta$-catenin levels. Furthermore, in Wnt-overexpressing PC12 cells, dominant-negative Akt decreases free $\beta$-catenin and depresses nerve growth factor-induced differentiation (Fukumoto et al., 2001).Thus, there is a multiprocessing role of GSK-3 in cellular signalling pathways in normal conditions and also a critical involvement in the pathophysiology of a number of diseases. Accordingly, excessive activation of GSK-3 is thought to cause pro-apoptotic effects after brain injury (Dash et al., 2011; Wu et al., 2013), ischemia/reperfusion (Valerio et al., 2011) and to phosphorylate tau protein provoking the development of Alzheimer's disease (Cai et al., 2012). It is also believed to be implicated in psychiatric conditions such as schizophrenia, bipolar disorder and major depression (Mao et al., 2009; Lipina et al., 2012; Luykx et al., 2010, O'Brien and Klein, 2007). Many of these pathologies are accompanied by cognitive deficits which clinically exacerbate the patient impact during disease progression.

Moreover, some investigations have identified a significant role of GSK-3 in normal memory mechanisms especially in stabilization (consolidation) and updating (reconsolidation) (Alberini, 2005, Alberini and Ledoux, 2013, Alberini et al., 2013) of memory trace or engram (Chen et al., 2011; Hong et al., 2012; Kimura et al., 2008; Wu et al., 2011). However, published data on this issue appear to be conflicting and it is interesting to note that in heterozygote GSK-3 knockout (GSK-3 $\beta+/-)$ mice, the contribution of the enzyme to memory has been detected in the reconsolidation phase but not in consolidation of the contextual fear conditioned memory trace (Kimura et al., 2008). On the other hand, GSK3 activation is required for insulin-like growth factor II (IGF-II)-dependent memory enhancement during memory trace consolidation in the experimental fear model (Chen et al., 2011). In addition, intrahippocampal injection of the GSK-3 $\beta$ inhibitor, SB 216763 before a retention session, blocked memory retrieval but not reconsolidation in a passive avoidance task without affecting animal locomotor activity. These results suggest that GSK-3 $\beta$ activation would be essential for memory retrieval in the hippocampus (Hong et al., 2012). This inconsistency may be explained by the fact that constitutively activated GSK-3 is involved at least in several distinct signalling pathways through a Ser9 phosphorylation enzyme-inhibited state (pGSK-3ßSer9) or a tyrosine 216 phosphorylation enzyme-activated form (pGSK-3ßTyr216) (Noël et al., 2011; Takashima, 2009). It has been pointed out that the frequent need to retrieve many memories under conditions when an individual is confronted with a new idea or task, leads in time, to over-activation of GSK-3 $\beta$. It could also 


\section{Learning ability, GSK-3 inhibition and memory}

be proposed that a frequent need to retrieve (especially, unsuccessful attempts to retrieve memory) in persons with mild cognitive decline, could in some cases provoke further worsening of memory functions and that GSK-3 $\beta$ is one of the key players in these processes (Jope and Roh, 2006, Takashima, 2012).

Plurality of regulatory pathways affecting GSK-3 activity may be the source of considerable variability of the enzyme inhibitors effects on cognitive function. In particular, lithium, directly inhibits GSK-3 $\beta$ activity, but in vivo, it indirectly inhibits the enzyme by regulating the formation of a signalling complex comprised of $\beta$-arrestin 2 ( $\beta$ Arr2) and Akt (Freland and Beaulieu, 2012). Hence lithium is regarded as a neuroprotective agent and cognitive enhancer (Tsaltas et al., 2009) but conversely, its neurotoxicity has also been reported to mimic rapidly progressive dementia (Mignarri et al., 2013). However, it must be borne in mind that such discrepancies may at least in part be ascribed to inconsistencies within the mental state of those patients studied.

Animal learning ability and how it may be linked with GSK-3 activity in spatial memory consolidation/reconsolidation (Alberini, 2005, Alberini and Ledoux, 2013, Alberini et al., 2013) is the focus of this study. Hence, a non-ATP competitive GSK-3 inhibitor, namely TDZD-8 (which binds to the active site of GSK-3 (Meijer et al., 2004) was employed to modify the activity of the enzyme in conditions of weak and strong memory on subjects in three classes of learning capacity. TDZD-8 protects the hippocampus from ischaemia/reperfusion injury (Collino et al., 2008) but there are no data concerning manipulations with this inhibitor on GSK-3-activity during the development of spatial performance with respect to varied learning ability. Consequently, the aim was to establish whether inherent visuospatial learning ability was influenced by GSK-3 inhibition and the retrieval procedure in the phase of learning when long-term spatial memory was being formed. Furthermore, task irrelevant anxiety has been hypothesised to compete with ongoing cognitive operations localised to the same neural circuitry (Shackman et al., 2006). Hence, it was necessary beforehand, to determine whether anxiety had any influence on the learning ability of animals in this study. 


\section{Materials and Methods}

All experimental procedures were carried out in accordance with: the National Institute of Health Guide for the Care and Use of Laboratory Animals (NIH Publications No. 80-23, revised 1996); the UK Animals Scientific Procedures Act 1986 and associated guidelines; the European Communities Council Directive of 24 November 1986 (86/609/EEC) for care and use of laboratory animals. They were also approved by the Animal Care and Use Committee of the P. K. Anokhin Institute of Normal Physiology, RAMS, Moscow, Russia.

\section{Chemicals}

Both 4-benzyl-2-methyl-1,2,4-thiadiazolidine-3,5-dione (TDZD-8), dimethylsulfoxide (DMSO) were obtained from Sigma-Aldrich, USA.

\section{Subjects}

Adult male Wistar rats weighing 220 $20 \mathrm{~g}(\mathrm{n}=96)$ were used throughout the study. The animals were obtained from Stolbavaya Laboratory Animal breeders (Moscow, Russia). They were allowed food and water ad libitum and housed in groups of three in standard laboratory cages under $12 \mathrm{~h}-12 \mathrm{~h}$ light-dark conditions at $21.0 \pm 1.0^{\circ} \mathrm{C}$.

\section{TDZD- 8 inhibition of GSK-3及}

\section{Hippocampal cell lysate production}

Four equal groups of rats $(n=12)$ were administered (i.p.) with TDZD-8 (1.0, 2.0 and 4.0 $\mathrm{mg} / \mathrm{kg}$ ) or vehicle. Animals were decapitated $30 \mathrm{~min}$ after drug administration and the hippocampus was removed bilaterally on ice and then transferred immediately to liquid nitrogen. Hippocampal tissue samples were thinly sliced and thawed in RIPA buffer (Pierce Biotechnology Inc., USA) containing 50mM Tris-HCI , pH 7.4, 1\% Nonidet NP-40, $0.5 \%$ Na-deoxycholate, $0.1 \%$ SDS, $150 \mathrm{mM} \mathrm{NaCI}, 2 \mathrm{mM}$ EDTA, 50mM NaF, $1 \mathrm{mM}$ PMSF in a proportion of $1.0 \mathrm{mg}$ tissue $/ 3.0 \mathrm{ml}$ of precold RIPA buffer. Each sample was individually homogenized using a SONOPULS mini20 sonicator (Bandelin Electronic $\mathrm{GmbH} \& \mathrm{Co} \mathrm{KG}$, Germany) at $+4^{\circ} \mathrm{C}$ and incubated on ice for $30 \mathrm{~min}$. Homogenates were then centrifuged at 
10,000g for $10 \mathrm{~min}$ at $+4^{\circ} \mathrm{C}$ (Eppendorf 5810R centrifuge, Germany). The supernatants were removed and centrifuged for a second time under the same conditions. The secondary supernatant fluids represented the total hippocampal cell lysates in which the protein concentration was determined using a Bradford protein assay kit (Pierce Biotechnology Inc., USA).

\section{GSK-3ß activity measurement: immunoprecipitation and kinase radioassay}

The measurement of GSK-3 activity was performed on total hippocampal cell lysates using a

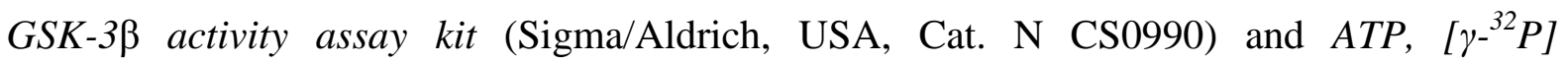
(PerkinElmer, USA). According to the commercial protocol, 300-600 $\mu \mathrm{l}(200 \mu \mathrm{g}$ of cell lysate protein) of hippocampal cell lysate samples were incubated on ice for 3 hours with EZview ${ }^{\mathrm{TM}}$ Red Protein G Affinity Gel beads preliminarily covered with monoclonal antiGSK-3 $\beta$ mouse antibodies. In addition to the protocol for each sample, the following negative control assays were employed: Negative Control 1 = kinase activity control without substrate and Negative Control $2=$ absence of the immunoprecipitating antibody or inhibition reaction. Tubes with immobilized antibody-antigen complexes on gel beads (3 repetitions per sample) were washed thrice using $0.5 \mathrm{ml}$ of wash buffer. Subsequently, the kinase reaction mixture

(GSK-3 $\beta$ peptide substrate, $5 \mu \mathrm{l}$; assay buffer, $12.5 \mu \mathrm{l}$; wash buffer, $7.5 \mu \mathrm{l}$; ATP, $\left[\gamma^{-32} \mathrm{P}\right]$, $2.5 \mu \mathrm{l}$ (with a specific activity of $10 \mathrm{mCi} / \mathrm{ml}$ ) was added to each tube, incubated for $30 \mathrm{~min}$ at $22 \pm 0.5^{\circ} \mathrm{C}$ and centrifuged at $8,000 \times \mathrm{g}$. Finally, $25 \mu \mathrm{l}$ of the reaction mixture was spotted onto squares of P81 cellulose phosphate paper, dried for $1 \mathrm{~min}$, washed fourfold with $10 \mathrm{ml}$ phosphoric acid (5 min) then once gently with ethanol $(1 \mathrm{~min})$ and finally, once with acetone ( $1 \mathrm{~min})$. Cellulose phosphate squares were dried at room temperature and the incorporated radioactivity was counted using the Cerenkov method (i.e counting the emission without scintillation liquid, using the tritium channel) by means of a 1219 Racbeta Liquid scintillation counter (LKB Wallac, Sweden). Results were represented in cpm and \% of cpm in samples from rats treated with vehicle. 
Elevated plus maze paradigm (EPM) evaluation of anxiety related behavior in inferior, intermediate and superior learner rats in the elevated plus maze

The inherent anxiety level of rats was evaluated using the elevated plus maze as a simple method for assessing this condition (Pellow et al., 1985; Walf and Frye, 2007). The apparatus (TSE Systems GmbH, Germany) consisted of two opposing open arms $(50 \times 10 \mathrm{~cm})$ and two facing closed arms $(60 \times 10 \mathrm{~cm})$ with $30 \mathrm{~cm}$ high, opaque walls. The four arms were connected by a central platform $(10 \times 10 \mathrm{~cm})$ and the maze was elevated by $72 \mathrm{~cm}$ above the floor. Rats selected randomly from the whole cohort $(n=24)$ were initially placed in the center of the maze facing one of the open arms and were then allowed to investigate the area for $5 \mathrm{~min}$. Their behavior was recorded by video-tracking via ETHOVISION (Noldus, Wageningen, Netherlands). Entry into each arm was defined when the animals front legs and head were entirely in the arm. The number of entries plus the time spent in the open and closed arms along with the entry numbers as well as the duration in the center, incidence of peering out of closed arms and defecation (bolus number) were measured to assess anxiety-related behavior (Geis et al., 20011). Elevated plus maze experiments were performed 12 days before water maze training. Subsequently, learning ability classification was retrospectively applied to the elevated plus maze performance in individual animals.

\section{Morris water maze paradigm (MWM)}

The Morris water maze consisted of a grey circular pool $(160 \mathrm{~cm}$ in diameter and $60 \mathrm{~cm}$ in height) filled to a depth of $40 \mathrm{~cm}$ with water at a temperature $22.0 \pm 1.0^{\circ} \mathrm{C}$. A transparent circular escape platform (12 cm in diameter) was located in the center of one quadrant of the

pool $2.0 \mathrm{cms}$ beneath the water surface. A videomonitoring system analysed via ETHOVISION (Noldus, Wageningen,

Netherlands) was used for recording visuospatial navigation (time to reach the platform i.e. swimming/escape latency). The maze was positioned in a well-lit room with several posters and other distal visual stimuli on the walls to provide external spatial cues (Sewell et al., 2005; Gruden et al., 2013). 


\section{Learning ability, GSK-3 inhibition and memory}

The rats were brought to a waiting room and kept in holding cages at least 30 min before the experiments. They were initially trained to locate spatially the hidden platform on 4 successive protocol days (Figure 1). Each day, individual animals underwent four consecutive training swimming trials with a fixed quadrant location of the hidden platform. Each trial was initiated by carefully placing the animal into the water facing the wall of the pool at one of three random start positions avoiding the quadrant containing the platform. In each trial, the time taken to escape onto the hidden platform (swimming latency, sec) was recorded and followed by a $15 \mathrm{sec}$ occupation time on the platform. The inter-trial period was $60 \mathrm{sec}$ and any animal that did not locate the platform within the $60 \mathrm{sec}$ epoch was gently guided on to it (Sewell et al., 2005; Gruden et al., 2013). This model is considered to generate robust short-term working and long-term reference memories in rats and there are even time-condensed adaptations of the water maze paradigm fulfilling these memory criteria (Gulinello et al., 2009; Feldman et al., 2010). Examination of mean escape latencies during days 1-4 of training indicated that memory consolidation (Rodriguez-Ortiz and Bermúdez-Rattoni, 2007) was initiated on the $3^{\text {rd }}$ day of learning and extended to 4 th day of training. (Figures 3-5). To study consolidation and reconsolidation of spatial memory in one protocol, it is customary to employ models in which memory has not been totally consolidated (Nader and Einarsson, 2010) therefore a 4-day MWM training schedule was chosen.

After completion of the last trial of the initial training session, animals were returned to home cages and on the $5^{\text {th }}$ protocol day, they were divided into three classifications of learning performers according to their mean swimming latencies obtained on the $4^{\text {th }}$ day of training (Figures 1 and 2). The first class $(\mathrm{n}=24)$ of higher performing animals were designated as "superior learners" and consisted of those subjects displaying mean escape latencies <8.75 sec. A second class, "intermediate learners" $(n=48)$, included rats demonstrating mean escape latencies $>8.75$ but $<16.5 \mathrm{sec}$. A third set, specified as "inferior learners" ( $n=24)$, consisted of rats exhibiting mean swimming latencies $>16.5 \mathrm{sec}$ (Figure 2).

Each designated learning class was further divided into four equal groups on day 5 of the protocol (Figure 1): group 1, was administered vehicle (0.1\% DMSO, $1.0 \mathrm{ml} / \mathrm{kg}$ i.p.) followed by exposure to a MWM trial in the absence of the platform. In this non-rewarded probe trial, each animal was allowed to swim until it succeeded in attaining the former platform location 


\section{Learning ability, GSK-3 inhibition and memory}

(always within $60 \mathrm{sec}$ ) at which time the animal was immediately lifted from the pool without an opportunity to gain platform access and this was termed a "retrieval trial" (Morris et al., 2006). Group 2 received TDZD-8 (2.0 mg/kg, i.p.) with an exposure to the retrieval trial procedure. Vehicle (i.p.) was administered in group 3, while group 4 received TDZD-8 (2.0 $\mathrm{mg} / \mathrm{kg}$, i.p.) and both latter groups were returned to their home cages without a retrieval trial (Figure 1). The particular dose of TDZD-8 was selected from the range $(1.0-4.0 \mathrm{mg} / \mathrm{kg})$ tested in our GSK-3 enzyme inhibition study and was additionally based on data that it caused a nearmaximal effect on Ser ${ }^{9}$ GSK-3ß phosphorylation (Collino et al., 2009) with the dose-response relationship approaching the asymptote. The dose also concurred with those employed in other behavioural studies (Collino et al., 2008; Lipina and Roder, 2010; Lipina et al., 2011; Kalinichev and Dawson, 2011).

Animal groups 1 and 2 were exposed to a swimming trial without the platform for $60 \mathrm{sec}$ and this stage of the protocol was termed "retrieval" since they always located the former site of the platform and this corresponded to the reconsolidation stage of memory (Alberini et al., 2013). On days 16-19 of the protocol (Figure 1), all animal groups were resubjected to spatial navigation training with identical spatial cues plus the same platform location and this process was termed "repeated learning". The time interval between initial and repeated training was chosen based on data concerning the strengthening of memory (in an inhibitory avoidance model) during a two week interval after initial training (Inda et al., 2011).

\section{Data analysis}

The results were statistically processed using Statistica 7.0 software and Kruskal-Wallis test, Mann-Whitney U test, Wilcoxon matched pairs test and Friedman ANOVA analyses were also performed. The elevated plus maze results were presented as medians (interquartile ranges). However, the MWM data was presented as means \pm standard error for the reason of clarity. 


\section{Results}

\section{Dose related inhibition of GSK-3ß activity by TDZD-8}

The biochemical assay was designed to verify the effects of TDZD-8 at different doses on GSK-3 $\beta$ activity. Since GSK-3 is an abundant enzyme in the central nervous system, particularly in the hippocampus, the study was performed in samples of hippocampal cell lysates in an additional animal cohort. Comparative results of GSK-3 $\beta$ inhibition by TDZD-8 at three doses were confirmed in comparison with controls. Thus, in the hippocampus of control rats, the activity of GSK-3 $\beta$ was determined as $75080 \pm 1074 \mathrm{cpm} / \mathrm{mg}$ of total protein. After administration of 1.0, 2.0 or $4.0 \mathrm{mg} / \mathrm{kg}$ TDZD-8, the GSK-3 $\beta$ activity had declined to $52000 \pm 2045 \mathrm{cpm} / \mathrm{mg}(69.2 \%) ; 20900 \pm 1700 \mathrm{cpm} / \mathrm{mg}(27.8 \%) ; 17655 \pm 1295$ (23.5\%) cpm/mg of total protein respectively which represented a graded inhibition of the enzyme. There was no statistical difference between inhibition of enzyme activity at the 2.0 and $4.0 \mathrm{mg} / \mathrm{kg}$ doses, therefore this justified the use of the $2.0 \mathrm{mg} / \mathrm{kg}$ dose in the behavioral experiments.

Negative controls 1 and 2 determined in control hippocampal samples were ascertained as $1200 \pm 119 \mathrm{cpm} / \mathrm{mg}$ and $1350 \pm 236 \mathrm{cpm} / \mathrm{mg}$ of total protein, respectively. Negative controls 1 and 2 determined in hippocampal samples after 1.0, 2.0 and $4.0 \mathrm{mg} / \mathrm{kg}$ TDZD-8 administration were disclosed as $950 \pm 124 \mathrm{cpm} / \mathrm{mg}$ and $1214 \pm 201 \mathrm{cpm} / \mathrm{mg} ; 1021 \pm 113$

$\mathrm{cpm} / \mathrm{mg}$ and $1185 \pm 169 \mathrm{cpm} / \mathrm{mg}$ of total protein; $998 \pm 101 \mathrm{cpm} / \mathrm{mg}$ and $1098 \pm 214 \mathrm{cpm} / \mathrm{mg}$ of total protein, respectively. The control inhibition reaction, performed according to the commercial protocol with the GSK-3 $\beta$ inhibitor working solution revealed a $15.6 \pm 2.3 \%$ decrease in GSK-3 $\beta$ activity.

\section{Evaluation of anxiety related behavior in inferior, intermediate and superior learner rats in the elevated plus maze}

The data obtained in the elevated plus maze (Table 1), indicated that the differences between animal cohorts in the level of anxiety were negligible. Thus, no significant differences were observed in the time spent in the open and closed arms and the center of the maze, in addition to the number of open or closed arm entries. The number of transitions between the closed arms and exits to the center were higher in the intermediate learners and lower in the superior learners. The incidence of gazing out from the closed arms was higher in intermediate learners 
than superior learners who exhibited a higher level of defecation (Table 1). It was concluded that such outcomes in the three cohorts would have had minimal influence on their learning ability.

\section{Spatial learning parameters in superior, intermediate and inferior learner rats in the Morris} water maze memory task under learning and earlier or later protocol retrieval conditions

The distribution of animals in terms of their time to reach the platform on the 4th day of training is shown in Figure 2 and this created the basis of the classification of animals as superior, intermediate and inferior learners. Thus, those animals displaying latencies $>16.5 \mathrm{~s}$ were in the upper quartile range (inferior learners). Subjects expressing latencies <8.75 s were in the lower quartile range (superior learners) whilst the remainder of the cohort encompassed 8.75 - 16.5 s (intermediate learners).

Statistical analysis revealed a significant difference between the mean escape latencies within all animal groups on the $4^{\text {th }}$ training day (Kruskal-Wallis test: $\left.\mathrm{H}(2, \mathrm{~N}=24)=18.16, P=0.0001\right)$.

Comparison of group mean escape latencies on the $4^{\text {th }}$ day of training by the Mann-Whitney U test exposed highly significant differences between the inferior learners versus intermediate $(\mathrm{Z}(6,12)=4.18, P<0.001)$ and superior learners $(\mathrm{Z}(6,6)=4.56, P<0.001)$. Additionally, on the same training day (i.e. day 4), a protracted escape latency was detected between intermediate versus superior learners $(\mathrm{Z}(6,12)=3.18, P<0.01)$. Moreover, comparison of the same behavioral parameters on the $3^{\text {rd }}$ training day unveiled marked differences between the mean escape latencies of inferior learners from superior and intermediate learners $(\mathrm{Z}(6,6)=2.91, P<0.05)$ and $(\mathrm{Z}(6,12)=2.98, P<0.05)$ respectively (Table 2$)$. It is interesting to note that comparison of task performance in different learner classes on the $4^{\text {th }}$ and $16^{\text {th }}$ trial days (i.e. 11 intervening training free days, Fig. 1) by Wilcoxon matched pairs test, revealed that inferior learners displayed lower mean escape latencies on the $16^{\text {th }}$ day (start of repeated learning) versus day 4 $(\mathrm{Z}(6,6)=2.84), P<0.05)$. Furthermore, it was perceived that superior learners demonstrated lengthier escape latencies in the first trial on the $16^{\text {th }}$ trial day compared with the first trial on the $4^{\text {th }}$ day $(Z(6,6)=2.76, P<0.05)$. We also observed that inferior learners, in contrast to superior learners, demonstrated significantly shorter escape latencies on the first trial of the $16^{\text {th }}$ training day compared with the first trial on day $4(\mathrm{Z}(6,6)=2.80, P<0.05)$ (Table 2$)$. 
Thus, the outcome differences in spatial learning parameters of the three ability classes of rats serve to justify the application of the experimental paradigm for subsequent study of GSK- 3 inhibition on diverse learning aptitudes in the navigation performance task, especially in the consolidation and reconsolidation phases of memory.

\section{Effects of the GSK-3 inhibitor TDZD-8 and recall on superior learner rat navigation performance}

To initiate examination of TDZD-8 effects with respect to retrieval (Figure 1) in the spatial performance task, statistical analysis was instigated firstly on the memory performance of the superior learner class. Hence, in all four groups of superior learners (vehicle plus home cage/no retrieval trial, TDZD-8 plus home cage/no retrieval trial, vehicle plus retrieval and TDZD-8 plus retrieval), escape latencies to the hidden platform on the first trial of the $5^{\text {th }}$ day (not graphically shown) were augmented relative to those of the $4^{\text {th }}$ training day $(Z(6,6)>2.12$, $P<0.05$ ) (Fig. 3A). Significant differences between the escape latencies of all groups were also found on the first trial of the $16^{\text {th }}$ trial day (repeated learning procedure) (Kruskal-Wallis test: $\mathrm{H}(3, \mathrm{~N}=24)=16.86, P=0.0008)$, the $17^{\text {th }}$ trial day (Kruskal-Wallis test: $\mathrm{H}(3, \mathrm{~N}=24)=10.39$, $P=0.0155)$ and the $18^{\text {th }}$ trial day (Kruskal-Wallis test: $\left.H(3, \mathrm{~N}=24)=9.78, P=0.0324\right)$.

It was noted that after TDZD-8 administration, superior learners kept in their home cages showed lower escape latency values than their vehicle controls on the $17^{\text {th }}(Z(6,6)=2.96$, $P<0.01)$ and 18th training days $(\mathrm{Z}(6,6)=2.68, P<0.05)$. Combination TDZD-8 with the retrieval protocol increased escape latencies in superior learners on the first trial of the $16^{\text {th }}$ training day versus the other three animal groups $(\mathrm{Z}(6,6)>2.18, P<0.05)$ (Fig. 3B). Throughout the duration of the $17^{\text {th }}-19^{\text {th }}$ training days, no differences in escape latency values were detected between superior learners receiving TDZD-8 kept in their home cages (no retrieval trial) and those undergoing the retrieval procedure.

Inhibition of GSK-3 twenty-four hours after the last training session at the retrieval trial stage (Figure 1, day 5) in superior learners (maintained in their home cages), hastened their latency 
to reach the platform, whereas the combinative treatment of TDZD-8 with the retrieval procedure impaired memory retention and had no significant influence on repeated learning.

\section{Effects of the GSK-3 inhibitor TDZD-8 and recall on intermediate learner rat navigation performance}

No effects of TDZD-8, retrieval or their combination were found in the experiments with any of the intermediate learner groups versus the controls (Figure 4A, B).

\section{Effects of the GSK-3 inhibitor TDZD-8 and retrieval on inferior learner rat navigation performance}

Statistical analysis of inferior learner escape latency group differences on the $16^{\text {th }}$ (KruskalWallis test: $\mathrm{H}(3, \mathrm{~N}=24)=9.52, P=0.0311), 17^{\text {th }}$ (Kruskal-Wallis test: $\mathrm{H}(3, \mathrm{~N}=24)=8.44$, $P=0.036)$ and $18^{\text {th }}$ (Kruskal-Wallis test: $\left.\mathrm{H}(3, \mathrm{~N}=24)=8.05, P=0.043\right)$ training days (Figure1) was carried out. It was shown that on the $16^{\text {th }}$ day at the repeated learning stage, the mean values of escape latency in three groups of the inferior learners (vehicle plus retrieval, TDZD-8 plus retrieval and TDZD-8 in the home cage) were significantly higher than the vehicle group maintained in their home cage (Figure 5A). However, no significant difference in mean escape latency was found between inferior learners from the vehicle group plus retrieval trial, TDZD8 group plus retrieval and the TDZD- 8 group in the home cage (absence of retrieval trial) (Figure 5A). Inferior learner animals administered vehicle expressed both mean and first escape latencies on the $16^{\text {th }}$ day of training (later protocol retrieval ) which were lower than the fourth training day $(\mathrm{Z}(6,6)>2.01, P<0.05)$. In the other inferior learner groups, there were no significant differences between mean escape times on the $4^{\text {th }}$ and $16^{\text {th }}$ trial days. However,

significant intergroup differences were detected between $1^{\text {st }}$ escape latency values on the $16^{\text {th }}$ trail day (Kruskal-Wallis test: $\mathrm{H}(3, \mathrm{~N}=24)=9.68, P=0.0214)$. Inferior learners from the vehicle plus retrieval and

the TDZD-8 plus home cage groups performed worse than animals in the vehicle plus their home cage group $(\mathrm{Z}(6,6)>2.73, P<0.05)$. 


\section{Learning ability, GSK-3 inhibition and memory}

Inferior learner rats from both groups which underwent the retrieval procedure manifested on the $16^{\text {th }}$ day (later protocol retrieval) longer $1^{\text {st }}$ escape latencies in comparison with those in the vehicle group returned to their home cage (Figure $5 \mathrm{~B} ;(\mathrm{Z}(6,6)=2.84, P<0.05)$. Scrutiny of the behavioral data during the 16-19 day period of repeated training were subjected to Friedman ANOVA analysis and inter-sessional differences were identified within the $1^{\text {st }}$ escape latencies of the vehicle-home cage group (ANOVA $\left.\chi^{2}(\mathrm{~N}=6, \mathrm{df}=3)=8.00, P<0.05\right)$, the vehicle + retrieval group (ANOVA $\chi^{2}(\mathrm{~N}=6, \mathrm{df}=3)=10.22, P<0.01$ ) and the TDZD-8-home cage group (ANOVA $\left.\chi^{2}(\mathrm{~N}=6, \mathrm{df}=3)=9.74, P<0.05\right)$. However, animals after TDZD-8 administration with retrieval trials displayed no intersessional differences $\left(\right.$ ANOVA $\left.\chi^{2}(\mathrm{~N}=6, \mathrm{df}=3)=2.19, P>0.1\right)$. On the $18^{\text {th }}$ day (i.e. $3^{\text {rd }}$ day of repeated training) inferior learners from the TDZD-8-recall group yielded higher values of first escape latency than subjects from the vehicle as well as

TDZD- 8 plus home cage groups. On the $19^{\text {th }}$ day (i.e the $4^{\text {th }}$ day of repeated training) the inferior learners treated with TDZD-8 combined with the retrieval procedure showed higher 1st escape latencies than animals of the other groups examined.

In summary, TDZD-8 administered in the absence of a retrieval trial impaired subsequent reconsolidation performance in inferior learners but enhanced it in superior learners whilst there was no modification of performance in the intermediate learner group compared to corresponding controls. In TDZD-8-treated subjects exposed to a retrieval trial, the pattern of outcomes was identical whereby impairment of reconsolidation occurred in inferior learners, enhancement in superior learners but there was no modification of performance in intermediate learners.

\section{Discussion}

The Morris water maze task, which is a hippocampus-dependent learning and memory test typically entailing between 3-14 days of training, was employed as a behavioral model (Sewell et al., 2005; Terry, 2009). This methodology has been used to evaluate not only navigation performance (Wood, 2011; Meck et al., 2013) but also a molecular continuum of mnestic and amnestic processes in animals. Learning ability on the other hand, has not been a primary focus of visuospatial performance studies particularly on consolidation (McGaugh, 2000) and reconsolidation (Alberini and Ledoux, 2013) memory phases in animals (Alberini, 


\section{Learning ability, GSK-3 inhibition and memory}

2005; Alberini et al., 2013; Sara, 2000) though some reports have been centered on the ageing brain in this respect (Samadani and Moussavi, 2012; Haberman et al., 2013). Consolidation has been regarded for some time as a memory stabilization process executed on newly acquired memories in order to store their traces for the long term (McGaugh, 2000; Suzuki et al., 2004). Certain studies have demonstrated that after initial retrieval, long term memories may once more undergo a consolidation-like process which is termed reconsolidation (Debiec et al., 2002; Rodriguez-Ortiz and Bermúdez-Rattoni, 2007) and this implicates independent cellular processes (Debiec et al., 2002; Lee et al., 2004). The stability of the memory trace is a principal indicator of learning ability in animals and humans (Matzel et al., 2003) since it has been reported that the stability of retrieved memory is inversely correlated with the control of behavior by that memory (Eisenberg et al., 2003). Hence, one of the aims of this study was to provide an answer to the question of how varied learning ability may be associated with stability and strength of memory trace in a spatial performance paradigm. The designations "superior", "intermediate" and "inferior" learners are defined only by the

parameters specifically imposed in this study and reflect only how fast the stability of the memory trace is established in the constant conditions of the chosen behavioral paradigm.

In the total animal cohort studied $(n=96), 3$ classes of rats with different inherent learning abilities were identified. These included superior learners (25\%), intermediate learners (50\%) and inferior learners (25\%) and this ability rank was used in subsequent studies. Any differences in the elevated plus maze behavioural pattern in the animal cohorts did not focus on the classical parameters of open arm versus closed arm entries (Pellow et al., 1985) and only very minor measures displayed any difference between groups. Hence it can be concluded that there were no major differences between superior, intermediate or inferior learners with respect to anxiety which might have influenced learning.

Memory phenomena and different learning abilities stem at least partially from an array of underlying molecular mechanisms, including protein synthesis (e.g. in the hippocampus), mRNA activation and consequent gene expression (Da Silva et al., 2008; Haberman et al., 2013; Gruden et al., 2013). It should also be noted that during the course of our experiments, superior and inferior learners could be readily differentiated by their speed of trace stabilization. This diversity in onset of memory trace reinforcement during initial training in both of these groups 
and its post-training modification probably arose from an innate variability of cognitive strategy, i.e., a balance between strength and flexibility of memory trace. In superior learners, the level of memory trace was higher and the retrieval procedure in the absence of the platform did not influence the established trace. The process of forgetting in superior learners examined 10 days after initial training probably served to increase the flexibility of behavior under a change of environment. This could reflect a rapid change of previously acquired habit if the environment (for example, visual cue positions) was changed. In inferior learners, an unstable and more flexible spatial memory trace was established. The stability of memory trace increased in the control inferior learners (vehicle in home cage i.e., no retrieval trial) during 10-days of rest without any changes in environment. In these rats, the recall procedure without the platform was the signal which prevented spatial memory trace stabilization based on greater trace flexibility. It could be proposed that in the group of intermediate learners (the majority of the study population), an optimal level of strength and flexibility of memory trace was achieved during initial training. Thus, neither retrieval without the platform nor 10-days rest, had any effect on trace. It may also be hypothesized that the balance between the flexibility and stability of spatial memory trace was not the underlying mechanistic process, but the result of complex interactions amongst different signal pathways, for example Wnt and/or the survival and apoptosis of newly generated neurons. In addition, long term potentiation (LTP) and long term depression (LTD) of hippocampal cells may contribute to these properties of spatial memory trace (Whitlock et al., 2006). It is notable that TDZD-8 was implicated in improved task acquisition during repeated learning in the superior learner group and the mechanism of this learner class phenomenon is the subject of future study.

Apart from the aforementioned processes which are the basis of novel memory formation, other molecular mechanisms can support memory trace stability. The stability of the memory trace is a principal indicator of learning ability in animals and humans (Matzel et al., 2003) since it has been reported that the stability of retrieved memory is inversely correlated with the control of behavior by that memory (Eisenberg et al., 2003).

In recent times, interest has been concentrated on GSK-3 as a regulator of glycogen metabolism, protein synthesis, cell growth, survival and programmed cell death (apoptosis) (Grimes et al., 2001; Cai et al., 2012). In normal physiological conditions, GSK-3 is thought to be a constitutively active kinase and most GSK-3 substrates are under negative regulation, 


\section{Learning ability, GSK-3 inhibition and memory}

which is reversed by Ser9 phosphorylation via other kinases such as protein kinase A and C (PKA and PKC) and protein kinase B (Akt) (Jope and Johnson, 2004; Kimura et al., 2008). Kimura et al., (2008) hypothesized that under normal conditions, GSK-3 $\beta$ is inhibited and as such, it does not appear to affect brain function. However, in disease states, the enzyme becomes stimulated by the elimination of inactivation signals. Notwithstanding this, there is evidence that GSK-3 $\beta$ may participate in learning and memory mechanisms whereby reconsolidation requires its activation (Kimura et al., 2008) and it is also involved in neuropathological states, where cognitive deficits are present (Jain et al., 2013). This concept is additionally supported by the importance of GSK-3 activity during the induction of LTD, suggesting that GSK-3 function may contribute to the control of synaptic plasticity coupled with learning and memory mechanisms (Peineau et al., 2008).

Thus, the next target of this study was to probe the effects of GSK-3 inhibition on long-term spatial memory dynamics with respect to inherent learning ability. We have therefore performed biochemical enzyme assays which have verified that TDZD-8 at a $2.0 \mathrm{mg} / \mathrm{kg}$ dose is an effective in vivo inhibitor of hippocampal GSK-3 $\beta$ activity. Hence, this particular dose of TDZD-8 was chosen for all behavioral investigations in this study. It is important at this juncture to appreciate that memory consolidation and reconsolidation have an intricate developmental chronology but a single drug exposure at a critical time point before or after training or reminding may be inductive (Nadel et al., 2012). Also, it is known that inhibition of consolidation by a single exposure to biologically active compounds leads to the deterioration of memory trace during long term testing (at least 7 days) (Parfitt et al., 2012). In addition, it has been observed that not only exposure to chemical agents, but even space in a new environment (e.g., non-associative learning in the hole-board model) may lead to longterm disruption of the memory trace. Furthermore, the combination of new training with memory reactivation (reconsolidation) causes suppression of skill reproduction 21 days after exposure (Boccia et al., 2005). Thus, prolongation of memory impairment after a single TDZD-8 exposure (i.e. GSK-3 inhibition) in this investigation has also been studied elsewhere though data suggests that GSK-3 performs a dual role. Hence, GSK-3 activity maintains cognitive function in persons without dementia, whereas excessive activation of GSK-3 occurs in cortical and neocortical regions of patients with dementia (Takashima, 2012). 


\section{Learning ability, GSK-3 inhibition and memory}

An experimental approach involving memory retrieval or its absence, with subsequent repeated learning was devised to investigate any possible modification in the consolidation and reconsolidation phases. It was found that in superior learners which demonstrated a high level of spatial navigation performance at the end of an initial training session, spontaneous extinction of memory trace occurred. This phenomenon was not affected by TDZD-8 but there was enhanced stable memory trace in the subsequent course of repeated learning in animals with no previous reconsolidation. Therefore inhibition of the enzyme at the consolidation stage improved subsequent reconsolidation of spatial memory trace (Figure 6). Hence, in superior learners, a stable memory trace was destabilized following GSK-3 inhibition but during a later retrieval procedure on the first day of a repeated learning program, it not only underwent stabilization, but also a reinforcement reflected by decreased mean escape latency as an expression of memory enhancement.

Interestingly, the retrieval procedure itself had no influence either on memory trace retrieval or the dynamics of memory trace throughout the course of repeated learning (Figure 6). Imposition of GSK-3 inhibition on the retrieval procedure significantly impaired memory trace retrieval on the $17^{\text {th }}$ protocol day but did not prevent memory restoration in the superior learners during the course of repeated learning.

The capacity of superior learners to boost memory trace after its stabilization provided them with the opportunity to improve/enhance spatial memory in the delayed conditions of the repeated learning procedure. This may be linked with the net product of a balance between enzyme activation and deactivation, the outcome of which may drive different molecular events underlying the formation of stable novel memory traces. The functional role of GSK-3 in the Wnt signalling pathway is pertinent to a GSK-3 involvement in the molecular regulation of spatial memory at the reconsolidation stage. Considering the animal learning ability data along with TDZD-8 effects, it might be hypothesised that the increased performance of superior learners after repeated training is associated with activation of the Wnt pathway by augmented expression of Wnt target genes. Moreover, Wnt signalling has a

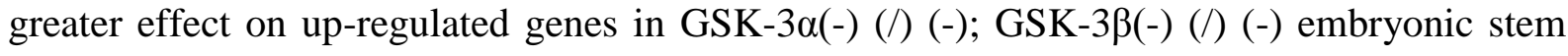
cells, whereas PI3K-dependent insulin signalling is more responsible for the down-regulation of genes in the same cells. These data emphasise the importance of GSK-3 activity on gene 
expression and such activity is due to the combined effects of multiple signalling pathways (Bartman et al., 2014).

In the light of this, intermediate learners did not exhibit any learning-related changes within the experimental protocol employed, so it may be deduced that consolidated memory trace is not affected by inhibition of GSK-3. In contrast, inferior learner rats did not express any extinction of memory trace and on the $16^{\text {th }}$ protocol day, they performed significantly better than on the $4^{\text {th }}$ day of initial training. This finding may be evidence of a "lingering" or "prolonged" consolidation phase of spatial memory (Dudai and Eisenberg, 2004) i.e., a timedependent spontaneous reinforcement of an unstable memory in this ability class of animals. The data indicate that TDZD-8 administration to rats returned to their home cage without the retrieval procedure evoked an impairment of prolonged consolidation of an unstable memory trace. This finding may be explained by an early GSK-3 participation in delayed memory enhancement through mechanisms of LTD which contributed to active synapse selection and "sharpening" of memory trace (Ge et al., 2010). Additionally, modified enzyme activity may bidirectionally modulate synaptic plasticity, serving as a connecting link between LTD and LTP (Peineau et al., 2007; 2008; Dewachter et al., 2009). It has been reasoned that a duality of influence on synaptic plasticity may shield synapses from additional NMDA receptordependent input until previous information was either consolidated or erased (Peineau et al. 2007; Zorumski and Izumi, 2012).

In inferior learners, TDZD-8 in combination with the recall procedure prevented spatial memory trace restoration during repeated learning (Figure 6). These data, to a certain extent, may correspond with results obtained by Kimura et al., (2008) which demonstrated that knockout (GSK-3 $\beta+/-$ ) mice exhibited retrograde amnesia with repeated training in the MWM paradigm. In the investigation, swimming with a platform absence impaired prolonged consolidation in inferior learners but did not affect spontaneous extinction in the superior learning animal class. It may be proposed that the retrieval procedure (Figures 1 and 6) caused partial memory extinction which interfered with prolonged consolidation of an unstable memory trace (Osan et al., 2011). However, non-reinforced retrieval can cause reconsolidation if the number of non-reinforced retrieval trials is insufficient to induce longlasting extinction (i.e. a single trial) then a hippocampal protein synthesis-dependent reconsolidation process recovers the original memory (Rosatto et al., 2006). It should be 
noted that in this case, there was partial erasure of memory trace which otherwise would have been consolidated or even enhanced. Furthermore, in inferior learners which were administered TDZD-8 together with a retrieval procedure, the partial erasure of memory trace coincided with failure of mechanisms which protect synapses and an untimely activation of NMDA-receptor input impairing LTP. This phenomenon may lead to development of a pathological form of metaplasticity and cognitive decline (Zorumaski and Izumi, 2012). The long-lasting effects of single TDZD-8 administration on spatial memory (especially, on the repeated learning end result) are evidence of its influence on continuing processes in the brain, such as cell proliferation, differentiation and survival. Moreover, the experimental data may suggest that a reduction in GSK-3 activity leads to suppression of intrinsic cell apoptosis (Song et al., 2010; Jaeger et al., 2013). Thus, administration of TDZD-8 at a dose $2.0 \mathrm{mg} / \mathrm{kg}$ may well decrease the rate of apoptosis in cells at an intermediate phase contributing to spatial memory formation (Epp et al., 2011). Additionally, there are data confirming that spatial learning modifies neurogenesis by stimulating a cascade of events that resembles the selective stabilization process characterizing development (Dupret et al., 2007). There are three interrelated events mediating spatial learning, that is, promotion of survival of relatively mature neurons, apoptosis of more immature cells, and finally, proliferation of neural precursors. Thus, blocking apoptosis impairs memory and inhibits learning-induced cell survival and cell proliferation. Dupret et al., (2007) concluded that during learning, similar to the selective stabilization process, neuronal networks are sculpted by a tightly regulated selection and suppression of different populations of newly born neurons. Supportive to this view are the findings that hippocampus-dependent learning in the MWM affects survival of immature cells even before they are synaptically contacted (Ambrogini et al., 2004; 2010). Correspondingly, survival of new born cells is increased during the initial phase of spatial learning, and diminished at the asymptotic phase, such phenomena being inculcated in stabilization of memory trace. Increased neural survival is therefore a prompt to new learning processes (Dupret et al., 2007). The specific dynamics of these processes has been examined in different species/strains and may depend on animal learning ability. In particular, survival of newly born neurons may be decreased by training on a difficult navigation task compared to a control level and relative to a simpler task (Epp et al., 2010). Differences in the effects of TDZD-8 in the superior and inferior learners may be associated with dissimilar rates of consolidation of spatial skills. In particular, consolidation was not established in inferior 
learners at the time of inhibitor administration in contrast to superior learners where memory trace stability was present.

In this study, the asymptotic phase was most likely achieved prior to TDZD-8 injection in superior learners. An increase in cell survival caused by injection of the GSK-3 inhibitor in the home cage was probably beneficial to repeated learning in superior learners at least. Conversely, inhibitor administration along with spatial memory destabilization (retrieval) in the superior learners led to mild impairment of navigation performance during the late recall procedure (Figures 1 and 6). Moreover, since the retrieval procedure was brief, it was likely that only a small population of newly born neurons was affected by combination of stimulus disparity (no retrieval) together with TDZD-8 and thus repeated learning was unimpaired in the superior learner group.

In inferior learners, the asymptotic level of spatial performance was not achieved but only began at the time of TDZD-8 injection. Selection of new neurons by apoptosis at this time may have occurred to generate further memory strengthening. If this "sculpturing" apoptosis was prevented by the GSK-3 inhibitor, it might have eventuated in consolidation impairment but not the prevention of repeated learning (injection in the home cage). Combination of retrieval with the action of the inhibitor could conceivably have enhanced the number of neuronal cells generated at the time and also after this disparity of training. This would be detrimental not only to late recall but also repeated learning.

In conclusion, the data substantiates the participation of GSK-3 in prolonged consolidation of an unstable spatial memory trace. Inhibition of this enzyme also impairs the process of reconsolidation in animals with a relatively stable spatial memory and prevents the restoration of disrupted habit in repeated learners with an unstable memory trace. In particular, subjects with superior learning ability exhibited improved reconsolidation following enzyme inhibition. These findings may aid the development of a strategy to use GSK-3 inhibitors for amelioration of cognitive deficits in different pathological states.

\section{Conflict of interest}

The authors declare no conflict of interest

\section{Funding}

This work was supported by the P. K. Anokhin Research Institute for Normal Physiology, Moscow, Russia. 


\section{References}

Alberini, C.M., 2005. Mechanisms of memory stabilization: are consolidation and reconsolidation similar or distinct processes? Trends Neurosci. 28, 51-56. doi:10.1016/j.tins.2004.11.001.

Alberini, C.M., Johnson, S.A., Ye, X., 2013. Memory Reconsolidation: Lingering consolidation and the dynamic memory trace, in: Alberini C.M. (Ed.), Memory reconsolidation. Elsevier, pp. 81-117. ISBN: 978-0-12-386892-3.

Alberini, C.M., Ledoux J.E., 2013. Memory reconsolidation. Curr. Biol. 23(17), R746-750. doi: 10.1016/j.cub.2013.06.046.

Ambrogini, P., Orsini, L., Mancini, C., Ferri, P., Ciaroni, S., Cuppini, R., 2004. Learning may reduce neurogenesis in adult rat dentate gyrus. Neurosci. Lett. 359, 13-6. http://dx.doi.org/10.1016/j.neulet.2003.12.123.

Ambrogini, P., Cuppini, R., Lattanzi, D., Ciuffoli, S., Frontini, A., Fanelli, M., 2010. Synaptogenesis in adult-generated hippocampal granule cells is affected by behavioral experiences. Hippocampus 20, 799-810. doi: 10.1002/hipo.20679.

Bartman, C.M., Egelston, J., Kattula, S., Zeidner, L.C., D'Ippolito, A., Doble, BW., Phiel, C.J., 2014. Gene expression profiling in mouse embryonic stem cells reveals glycogen synthase kinase-3-dependent targets of phosphatidylinositol 3-kinase and Wnt/ $\beta$-catenin signalling pathways.

Front Endocrinol (Lausanne) 5, 133. doi: 10.3389/fendo.2014.00133. eCollection 2014.

Boccia, M.M.1., Blake, M.G., Acosta, G.B., Baratti, C.M. 2005. Memory consolidation and reconsolidation of an inhibitory avoidance task in mice: effects of a new different learning task. Neuroscience. 135, 19-29.

doi: 10.1016/j.neuroscience.2005.04.068 
Cai, Z., Zhao, Y., Zhao, B., 2012. Roles of glycogen synthase kinase 3 in Alzheimer's disease. Curr. Alzheimer Res. 9, 864-79. d doi: 10.2174/156720512802455386.

Chen, D.Y., Stern, S.A., Garcia-Osta, A., Saunier-Rebori, B., Pollonini, G., Bambah-Mukku, D., Blitzer, R.D., Alberini, C.M., 2011. A critical role for IGF-II in memory consolidation and enhancement. Nature 469, 91-497. doi:10.1038/nature09667.

Collino, M., Aragno, M., Castiglia, S., Tomasinelli, C., Thiemermann, C., Boccuzzi, G., Fantozzi, R., 2009. Insulin reduces cerebral ischemia/reperfusion injury in the hippocampus of diabetic rats: a role for glycogen synthase kinase-3beta. Diabetes 58, 235-242. doi: 10.2337/db08-0691.

Collino, M., Thiemermann, C., Mastrocola, R., Gallicchio, M., Benetti, E., Miglio, G., Castiglia, S., Danni, O., Murch, O., Dianzani, C., Aragno, M., Fantozzi, R., 2008. Treatment with the glycogen synthase kinase-3beta inhibitor, TDZD-8, affects transient cerebral ischemia/reperfusion injury in the rat hippocampus. Shock 30, 99-307. doi: 10.1097/SHK.0b013e318164e762.

Da Silva, W.C., Bonini, J.S., Bevilaqua, L.R., Medina, J.H., Izquierdo, I., Cammarota, M., 2008. Inhibition of mRNA synthesis in the hippocampus impairs consolidation and reconsolidation of spatial memory. Hippocampus 18, 29-39. doi: 10.1002/hipo.20362.

Dash, P.K., Johnson, D., Clark, J.., Orsi1, S.A., Zhang, M., Zhao, J., Grill, R.J, Moore, A.N., Pati, S., 2011. Involvement of the Glycogen Synthase Kinase-3 Signalling Pathway in TBI Pathology and Neurocognitive Outcome. PLoS One 6, e24648. doi: 10.1371/journal.pone.0024648.

Debiec, J., LeDoux, JE., Nader, K., 2002. Cellular and systems reconsolidation in the hippocampus. Neuron 36, 527-538. doi.org/10.1016/S0896-6273(02)01001-2 


\section{Learning ability, GSK-3 inhibition and memory}

Dewachter, I., Ris, L., Jaworski, T., Seymour, C.M., Kremer, A., Borghgraef, P., De Vijver, H., Godaux, E., Van Leuven, F., 2009. GSK3beta, a centre-staged kinase in neuropsychiatric disorders, modulates long term memory by inhibitory phosphorylation at serine-9. Neurobiol. Dis. 35, 193-200. doi: 10.1016/j.nbd.2009.04.003

Dudai, Y., Eisenberg, M., 2004. Rites of passage of the engram: reconsolidation and the lingering consolidation $\quad$ hypothesis. Neuron 44, 93-100. doi.org/10.1016/j.neuron.2004.09.003

Dupret, D., Fabre, A., Döbrössy, M.D., Panatier, A., Rodríguez, J.J., Lamarque, S., Lemaire, V., Oliet, S.H., Piazza, P.V., Abrous, D.N., 2007. Spatial learning depends on both the addition and removal of new hippocampal neurons. PLoS Biol. 5, e214. doi: 10.1371/journal.pbio.0050214

Eisenberg, M., Kobilo, T., Berman, D.E., Dudai, Y., 2003. Stability of retrieved memory: inverse correlation with trace dominance. Science 301, 1102-1104. doi: 10.1126/science. 1086881

Epp, J.R., Haack, A.K., Galea. L.A., 2011. Activation and survival of immature neurons in the dentate gyrus with spatial memory is dependent on time of exposure to spatial learning and age of cells at examination. Neurobiol. Learn. Mem. 95, 316-25. doi: 10.1016/j.nlm.2011.01.001.

Feldman, L.A., Shapiro, M.L., Nalbantoglu, J., 2010. A novel, rapidly acquired and persistent spatial memory task that induces immediate early gene expression. Behav. Brain Funct. 6, 35. doi: 10.1186/1744-9081-6-35.

Freland, L., Beaulieu, J.M., 2012. Inhibition of GSK3 by lithium, from single molecules to signalling networks. Front Mol Neurosci. 5, 14. doi: 10.3389/fnmol.2012.00014. 
Fukumoto S., Hsieh, C-M., Maemura K., Layne M.D., Yet, S-F., Lee, K-H., Matsui, T., Rosenzweig A., Taylor W.G., Rubin J.S., Perrella M., Lee M-E., 2001. Akt participation in the Wnt signalling pathway through Dishevelled. J Biol Chem. 276, 17479-17483.

Ge, Y., Dong, Z., Bagot, R.C., Howland, J.G., Phillips, A.G., Wong, T.P., Wang, Y.T., 2010. Hippocampal long-term depression is required for the consolidation of spatial memory. Proc. Natl. Acad. Sci. U S A. 107, 16697-16702. doi: 10.1073/pnas.1008200107.

Geis, C., Weishaupt, A., Grünewald, B., Wultsch, A., Reif, A., Gerlach, M., Dirkx, R., Solimena, M., Perani, D., Heckmann, M., Toyka, K.V., Folli, F., Sommer, C. 2011. Human stiff-person syndrome IgG induces anxious behavior in rats. PLoS One 6(2): e16775. doi: 10.1371/journal.pone.0016775

Gersten, M., Zhou, D., Azad, P., Haddad, G.G., Subramaniam, S., 2014. Wnt pathway activation increases hypoxia tolerance during development. PLoS One. 9(8):e103292. doi: 10.1371/journal.pone.0103292. eCollection 2014;

Grimes, C.A., Jope, R.S., 2001. The multifaceted roles of glycogen synthase kinase 3beta in cellular signalling. Prog. Neurobiol. 65, 391-426. doi.org/10.1016/S0301-0082(01)00011-9

Gruden, M.A., Storozheva, Z.I., Sewell, R.D.E., Kolobov, V.V., Sherstnev, V.V., 2013. Distinct functional brain regional integration of Casp3, Ascl1 and S100a6 gene expression in spatial memory. Behav. Brain. Res. 252, 230-238. doi: 10.1016/j.bbr.2013.06.024.

Gulinello, M., Gertner, M., Mendoza, G., Schoenfeld, B.P., Oddo, S., LaFerla, F., Choi, C.H., McBride, S.M., Faber, D.S., 2009. Validation of a 2-day water maze protocol in mice. Behav. Brain. Res. 196, 220-227. doi.org/10.1016/j.bbr.2008.09.002.

Haberman, R.P., Colantuoni, C., Koh, M.T., Gallagher, M., 2013. Behaviorally activated mRNA expression profiles produce signatures of learning and enhanced inhibition in aged rats with preserved memory. PLoS One 8(12), e83674. doi: 10.1371/journal.pone.0083674. 
Harwood, A.J., 2001. Regulation of GSK-3: a cellular multiprocessor. Cell. 105:821-824.

Hauser, M.D., Wood, J.N., 2010. Evolving the capacity to understand actions, intentions and goals. Ann. Rev. Psychol. 61, 303-324. doi:10.1146/annurev.psych.093008.100434

Hong, J.G., Kim, D.H., Lee, C.H., Park, S.J., Kim, J.M., Cai, M., Jang, D.S., Ryu, J.H., 2012. GSK-3 $\beta$ activity in the hippocampus is required for memory retrieval. Neurobiol. Learn. Mem. 98, 122-129. doi: 10.1016/j.nlm.2012.07.003.

Hutchings, E.J., Waller, J.L., Terry, A.V.Jr., 2013. Differential long-term effects of haloperidol and risperidone on the acquisition and performance of tasks of spatial working and short-term memory and sustained attention in rats. J. Pharmacol. Exp. Ther. 347, 547-56. doi: 10.1124/jpet.113.209031.

Inda, M.C., Muravieva, E.V., Alberini, C.M., 2011. Memory retrieval and the passage of time: from reconsolidation and strengthening to extinction. J. Neurosci. 31, 1635-1643. doi: 10.1523/JNEUROSCI.4736-10.2011.

Jaeger, A., Baake, J., Weiss, D.G., Kriehuber, R., 2013. Glycogen synthase kinase-3beta regulates differentiation-induced apoptosis of human neural progenitor cells. Int. J. Dev. Neurosci. 31, 61-68. doi: 10.1016/j.ijdevneu.2012.10.005.

Jain, V., Baitharu, I., Prasad, D., Ilavazhagan, G., 2013. Enriched environment prevents hypobaric hypoxia induced memory impairment and neurodegeneration: role of BDNF/PI3K/GSK3 $\beta$ pathway coupled with CREB activation. PLoS One 8(5), e62235. doi: 10.1371/journal.pone.0062235.

Jope, R.S., Johnson, G.V., 2004. The glamour and gloom of glycogen synthase kinase-3. Trends Biochem. Sci. 29, 95-102. http://dx.doi.org/10.1016/j.tibs.2003.12.004.

Jope, R.S., Roh, M.S., 2006. Glycogen synthase kinase-3 (GSK3) in psychiatric diseases and therapeutic interventions. Curr Drug Targets. 7, 1421-1434. 
Kalinichev, M., Dawson, L.A., 2011. Evidence for antimanic efficacy of glycogen synthase kinase-3 (GSK3) inhibitors in a strain-specific model of acute mania. Int $\mathbf{J}$ Neuropsychopharmacol. 14, 1051-1067.

Kim, Y., Lee, Y.I., Seo, M., Kim, S.Y., Lee, J.E., Youn, H.D., Kim, Y.S., Juhnn, Y.S., 2009. Calcineurin dephosphorylates glycogen synthase kinase-3 beta at serine-9 in neuroblastderived cells. J. Neurochem. 111, 344-354. doi: 10.1111/j.1471-4159.2009.06318.x.

Kimura,T., Yamashita, S., Nakao, S., Park, J., Murayama, M., Mizoroki, T., Yoshiike, Y., Sahara, N., Takashima, A., 2008. GSK-3beta is required for memory reconsolidation in adult brain. PLoS One 3, e3540. doi: 10.1371/journal.pone.0003540.

Lee, J.L.C., Everitt, B.J., Thomas, K.L., 2004. Independent cellular processes for hippocampal memory consolidation and reconsolidation. Science 30, 839-843. doi: 10.1126/science. 1095760

Li, Y.C., Wang, M.J., Gao, W.J., 2012. Hyperdopaminergic modulation of inhibitory transmission is dependent on GSK-3 $\beta$ signalling-mediated trafficking of GABAA receptors. J. Neurochem. 122, 308-320. doi: 10.1111/j.1471-4159.2012.07790.x.

Lipina, T.V., Kaidanovich-Beilin, O., Patel, S., Wang, M., Clapcote, S.J., Liu, F., Woodgett, J.R., Roder, J.C., 2011. Genetic and pharmacological evidence for schizophrenia-related disc1 interaction with GSK-3. Synapse 65, 234-48.

Lipina, T.V., Roder, J., 2010. A new model of the disrupted latent inhibition on C57BL/6Jmice. Psychopharmacol. 208, 487-498.

Lipina, T.V., Wang, M., Liu, F., Roder, J.C., 2012. Synergistic interactions between PDE4B and GSK-3: DISC1 mutant mice. Neuropharmacology 62, 1252-62. doi: 10.1016/j.neuropharm.2011.02.020. 
Luykx, J.J., Boks, M.P., Terwindt, A.P., Bakker, S., Kahn, R.S., Ophoff, R.A., 2010. The involvement of GSK3beta in bipolar disorder: integrating evidence from multiple types of genetic studies. Eur. Neuropsychopharmacol. 20, 357-368.

doi: 10.1016/j.euroneuro.2010.02.008.

Mao, Y., Ge, X, Frank, C.L., Madison, J., Koehler, A.N., Doud, M.K., Tassa, C., Berry, E.M., Petryshen, T.L., Soda, T., Biechele, T., Moon, R.T., Haggarty, S.J., Tsai, L.H., 2009. DISC1 regulates neural progenitor proliferation via modulation of GSK3 $\beta / \beta$-catenin signalling. Cell 136, 1017-1031. doi: 10.1016/j.cell.2008.12.044.

Matzel, L.D., Han, Y.R., Grossman, H., Karnik, M.S., Patel, D., Scott, N., Specht, S.M., Gandhi, C.C., 2003. Individual differences in the expression of a "general" learning ability in mice. J. Neurosci. 23, 6423-6433.

McGaugh, J.L., 2000. Memory - a century of consolidation. Science 287(5451), 248-251. doi: $10.1126 /$ science.287.5451.248.

Meck, W.H., Church, R.M., Matell, M.S., 2013. Hippocampus, time, and memory - a retrospective analysis. Behav. Neurosci. 127(5), 642-654. doi: 10.1037/a0034201.

Meijer, L., Flajolet, M., Greengard, P., 2004. Pharmacological inhibitors of glycogen synthase kinase 3. Trends Pharmacol. Sci. 25, 471-480. doi:10.1016/j.tips.2004.07.006

Mignarri, A., Chini, E., Rufa, A., Rocchi, R., Federico, A., Dotti, M.T., 2013. Lithium neurotoxicity mimicking rapidly progressive dementia. J. Neurol. 260, 1152-1154. doi: 10.1007/s00415-012-6820-z.

Morris, R.G.M., Inglis, J., Ainge, J.A., Olverman,H.J., Tulloch, J., Dudai, Y., Kelly, P.A.T., 2006. Memory reconsolidation: sensitivity of spatial memory to inhibition of protein synthesis in dorsal hippocampus during encoding and retrieval. Neuron 50, 479-489. 
Nadel, L., Hupbach A., Gomez, R., Newman-Smith, K., 2012. Memory formation, consolidation and transformation. Neurosci Biobehav Rev. 7, 1640-1645 doi: 10.1016/j.neubiorev.2012.03.001.

Nader, K., Einarsson, E.O., 2010. Memory reconsolidation: an update. Ann N Y Acad Sci. 1191:27-41 doi: 10.1111/j.1749-6632.2010.05443.x

Noël, A., Barrier, L., Rinaldi, F., Hubert, C., Fauconneau, B., Ingrand, S., 2011. Lithium chloride and staurosporine potentiate the accumulation of phosphorylated glycogen synthase kinase $3 \beta /$ Tyr216, resulting in glycogen synthase kinase $3 \beta$ activation in SH-SY5Y human neuroblastoma cell lines. J. Neurosci. Res. 89, 755-763. doi: 10.1002/jnr.22587.

O’Brien, W.T., Klein, P.S., 2007. Regulation of GSK-3 in patients with affective disorders. Biol. Psychiat. 61, 139-141. doi: 10.1016/j.biopsych.2006.11.008

Osan, R., Tort, A.B., Amaral, O.B., 2011. A mismatch-based model for memory reconsolidation and extinction in attractor networks. PLoS One 6, e23113. doi: 10.1371/journal.pone.0023113.

Parfitt, G.M., Campos, R.C., Barbosa, A.K., Koth, A.P., Barros, D.M., 2012. Participation of hippocampal cholinergic system in memory persistence for inhibitory avoidance in rats. Neurobiol Learn Mem. 97, 183-8. doi: 10.1016/j.nlm.2011.12.001.

Peineau, S., Bradley, C., Taghibiglou, C., Doherty, A., Bortolotto, Z.A., Wang, Y.T., Collingridge, G.L., 2008. The role of GSK-3 in synaptic plasticity. Br. J. Pharmacol. 153 (Suppl), S428-S437.

doi: 10.1038/bjp.2008.2.

Peineau, S., Taghibiglou, C., Bradley, C., Wong, T.P., Liu, L., Lu, J., Lo, E., Wu, D., Saule, E., Bouschet, T., Matthews, P., Isaac, J.T., Bortolotto, Z.A., Wang, Y.T., Collingridge, G.L., 2007. LTP inhibits LTD in the hippocampus via regulation of GSK3beta. Neuron 53, 703717. 
doi: 10.1016/j.neuron.2007.01.029.

Pellow, S., Chopin, P., File, S.E., Briley, M., 1985.Validation of open : closed arm entries in an elevated plus-maze as a measure of anxiety in the rat. J Neurosci Meth. 14, 149-167.

Perez-Costas, E., Gandy, J.C., Melendez-Ferro, M., Roberts, R.C., Bijur, G.N., 2010. Light and electron microscopy study of glycogen synthase kinase-3beta in the mouse brain. PLoS One 5, e8911. doi: 10.1371/journal.pone.0008911.

Rodriguez-Ortiz, C.J., Bermúdez-Rattoni, F., 2007. Memory reconsolidation or updating consolidation? in: Bermúdez-Rattoni, F., (Ed.) Neural plasticity and memory: from genes to brain imaging. CRC Press, Boca Raton, pp. 209-224. doi: 10.1201/978142000841.ch11.

Rossato, J.I., Bevilaqua, L.R.M., Medina, J.H., Izquierdo, I., Cammarota, M., 2006. Retrieval induces hippocampal-dependent reconsolidation of spatial memory. Learn Mem. 13, 431-40.

Samadani, A.A., Moussavi, Z., 2012. The effect of aging on human brain spatial processing performance. Conf. Proc. IEEE. Eng. Med. Biol. Soc. 2012, 6768-6771. doi: 10.1109/EMBC.2012.6347548.

Sara, S.J., 2000. Retrieval and reconsolidation: toward a neurobiology of remembering. Learn. Mem. 7, 73-84. doi: 10.1101/lm.7.2.73.

Sewell, R.D.E., Gruden, M.A., Pache, D.M., Storogeva, Z.I., Kostanyan, I.A., Proshin, A.T., Yurasov, V.V., Sherstnev, V.V., 2005. Does the human leukaemia differentiation factor fragment HLDF6 improve memory via brain DNA and protein synthesis? J. Psychopharmacol. 19, 602-608. doi: 10.1177/0269881105056645.

Shackman, A.J., Sarinopoulos, I., Maxwell, J.S., Pizzagalli, D.A., Lavric, A., Davidson, R.J., 2006. Anxiety selectively disrupts visuospatial working memory. Emotion. 6, 40-61. 


\section{Learning ability, GSK-3 inhibition and memory}

Sierksma, A.S., van den Hove, D.L., Pfau, F., Philippens, M., Bruno, O., Fedele, E., Ricciarelli, R., Steinbusch, H.W., Vanmierlo, T., Prickaerts, J., 2014. Improvement of spatial memory function in APPswe/PS1dE9 mice after chronic inhibition of phosphodiesterase type 4D. Neuropharmacology 77, 120-130. doi: 10.1016/j.neuropharm.2013.09.015.

Song, B., Lai, B., Zheng, Z., Zhang, Y., Luo, J., Wang, C., Chen, Y., Woodgett, J.R., Li, M., 2010. Inhibitory phosphorylation of GSK-3 by CaMKII couples depolarization to neuronal survival. J. Biol. Chem. 285, 41122-41134. doi: 10.1074/jbc.M110.130351.

Sternberg, R.J., Kaufman, J.C., 1998. Human abilities. Annu. Rev. Psychol. 49, 479-502. doi: 10.1146/annurev.psych.49.1.479.

Suzuki, A., Josselyn, S.A., Frankland, P.W., Masushige, S., Silva, A.J., Kida, S., 2004. Memory reconsolidation and extinction have distinct temporal and biochemical signatures. J. Neurosci. 24, 4787-4795. doi: 10.1523/JNEUROSCI.5491-03.2004.

Tabatadze, N., Tomas, C., McGonigal, R., Lin, B., Schook, A., Routtenberg, A., 2012. Wnt transmembrane signalling and long-term spatial memory. Hippocampus. 22, 1228-1241. doi: 10.1002/hipo.20991

Takashima, A., 2009. Drug development targeting the glycogen synthase kinase-3beta (GSK-3beta)-mediated signal transduction pathway: role of GSK-3beta in adult brain. J. Pharmacol. Sci. 109, 174-178. $\quad$ http://dx.doi.org/10.1254/jphs.08R29FM.

Takashima, A., 2012. GSK-3 $\beta$ and memory formation. Front. Mol. Neurosci. 5, 47(1-5). doi: 10.3389/fnmol.2012.00047.

Terry, A.V. Jr., 2009. Spatial navigation (water maze) tasks, in: Buccafusco, J.J., (Ed.) Methods of behavior analysis in neuroscience. 2nd ed. CRC Press; Boca Raton 2009. Chap. 13. ISBN-13: 978-1-4200-5234-3 
Tsaltas, E., Kontis, D., Boulougouris, V., Papadimitriou, G.N., 2009. Lithium and cognitive enhancement: leave it or take it? Psychopharmacol. 202, 457-476. doi: 10.1007/s00213008-1311-8.

Valerio, A., Bertolotti, P., Delbarba, A., Perego, C., Dossen, M., Ragni, M., Spano, P., Carruba, M.O., De Simoni, M.G., Nisoli, E., 2011. Glycogen synthase kinase-3 inhibition reduces ischemic cerebral damage, restores impaired mitochondrial biogenesis and prevents ROS production. J. Neurochem. 116, 1148-1159. doi: 10.1111/j.1471-4159.2011.07171.x.

Walf, A.A., Frye, C.A., 2007. The use of the elevated plus maze as an assay of anxiety-related behavior in rodents. Nature Protocols 2, 322-328.

Whitlock, J.R., Heynen, A.J., Shuler, M.G., Bear, M.F., 2006. Learning induces long-term potentiation in the hippocampus. Science 313(5790), 1093-1097. doi: 10.1126/science. 1128134

Wood, J.N., 2011. When do spatial and visual working memory interact? Atten. Percept. Psychophys. 73, 420-439. doi: 10.3758/s 13414-010-0048-8.

Wu, P., Xue, Y.X., Ding, Z.B., Xue, L.F., Xu, C.M., Lu, L., 2011. Glycogen synthase kinase $3 \beta$ in the basolateral amygdala is critical for the reconsolidation of cocaine reward memory. J. Neurochem. 118, 113-125. doi: 10.1111/j.1471-4159.2011.07277.x.

Wu, X., Mao, H., Liu, J., Xu, J., Cao, J, Gu, X., Cui, G., 2013. Dynamic change of SGK expression and its role in neuron apoptosis after traumatic brain injury. Int. J. Clin. Exp. Pathol. 6. 1282-1293. www.ijcep.com/ISSN:1936-2625/IJCEP1304023.

Zorumski, C.F., Izumi, Y., 2012. NMDA receptors and metaplasticity: Mechanisms and possible roles in neuropsychiatric disorders. Neurosci. Biobehav. Rev. 36, 989-1000. doi: 10.1016/j.neubiorev.2011.12.011. 


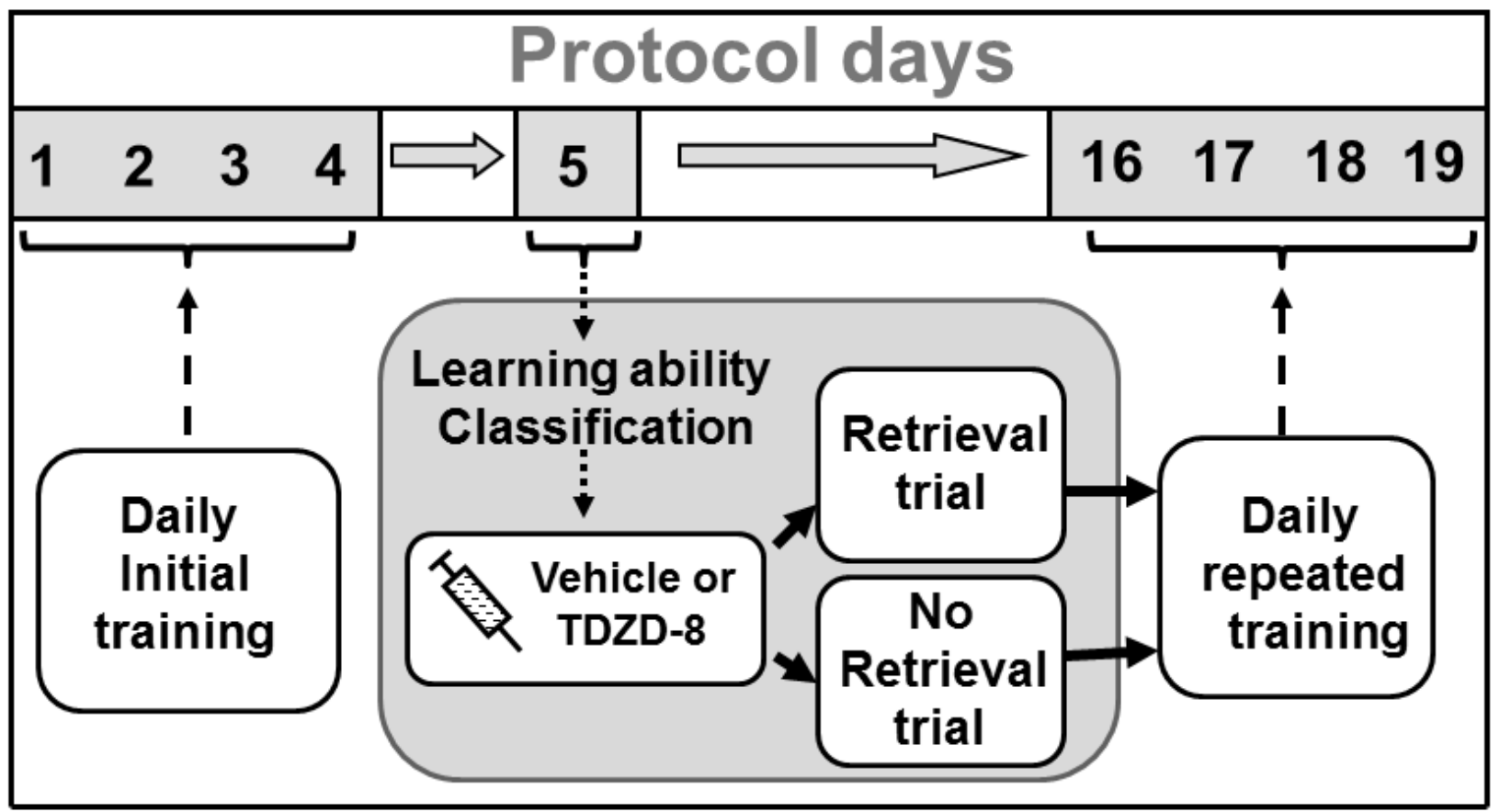

Figure 1 - Scheme showing the experimental protocol initiated by Morris water maze (MWM) training on days 1-4, then on day 5, learning ability classification (inferior, intermediate or superior learners), intraperitoneal (i.p.) injection of vehicle or TDZD-8 (2.0 $\mathrm{mg} / \mathrm{kg}$ ) followed by either a retrieval trial or no retrieval trial before return of animals to the home cage. Then on days 16-19, repeated MWM training. 


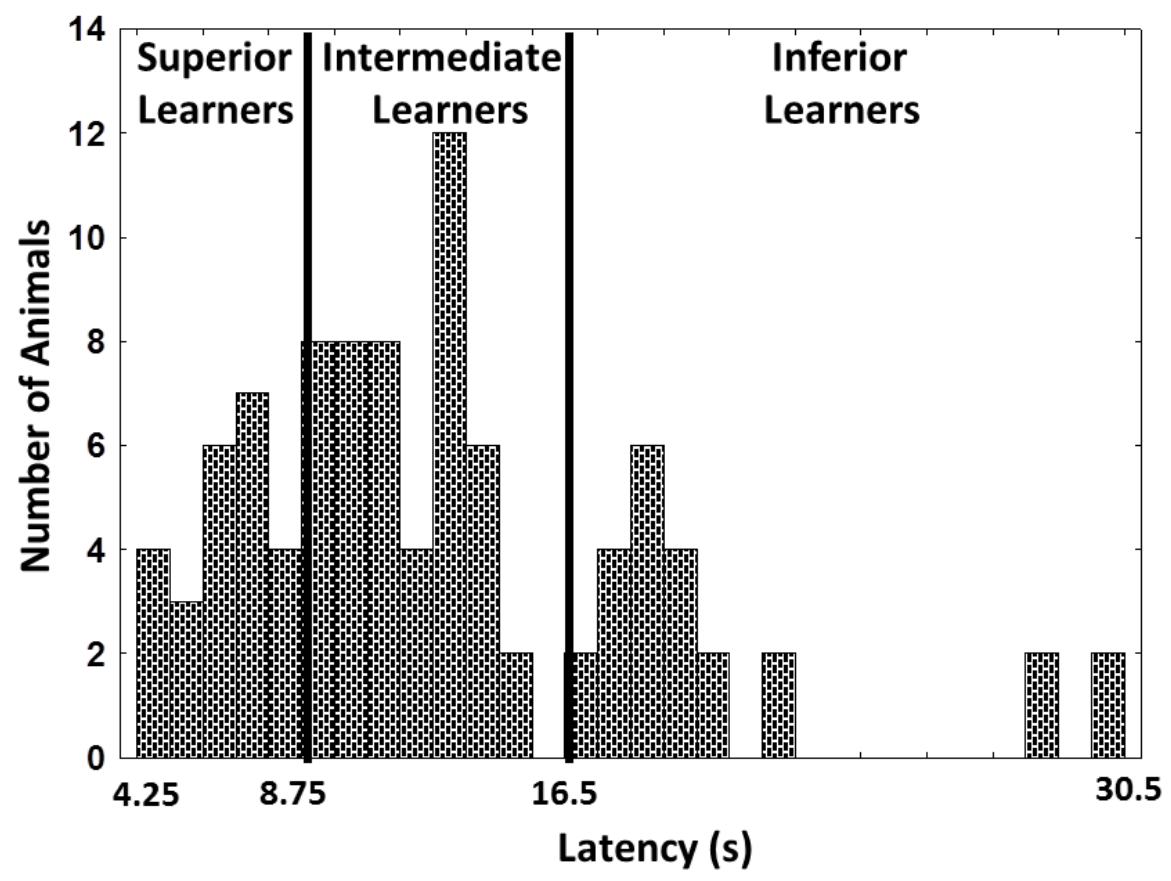

Figure 2 - Distribution of superior, intermediate and inferior learner rats based on their platform escape latencies (s) on the $4^{\text {th }}$ protocol training day.

\section{Superior Learners}
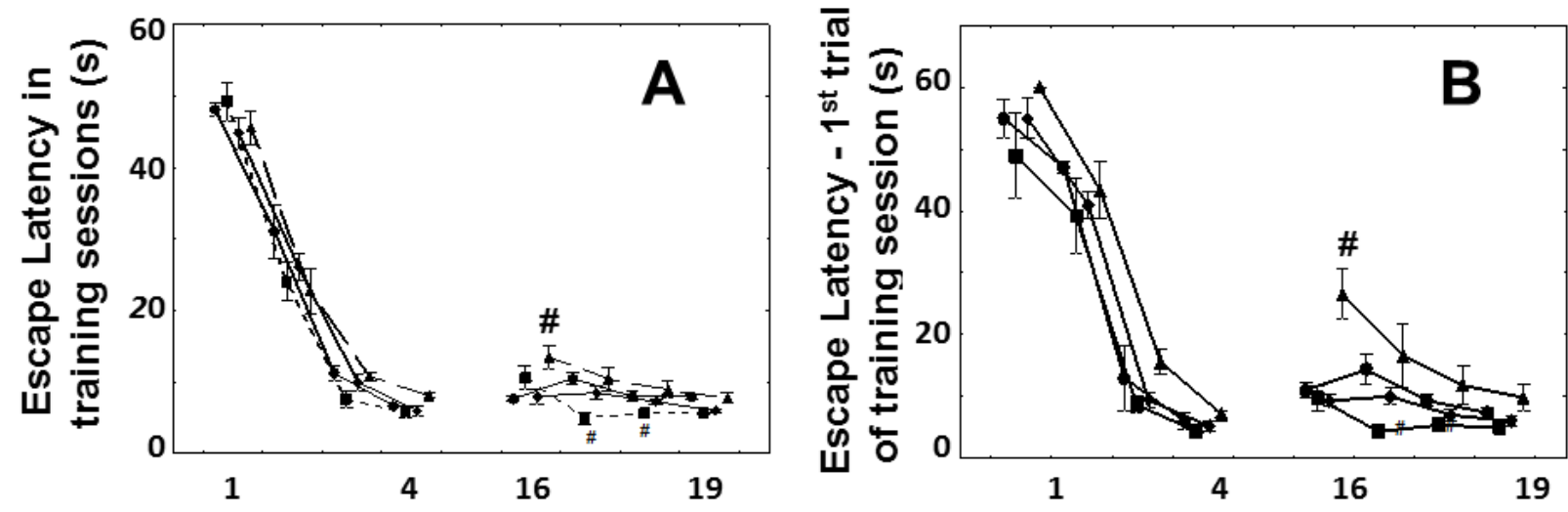

\section{Protocol Days}

Figure 3 - (A) Daily overall trial- and (B) first trial-swimming escape latencies (s, mean \pm sem) of superior learner rats in the Morris water maze on protocol days 1-4 and 16-19. Animals received i.p. on day 5: vehicle and no retrieval trial before home cage return (circles), TDZD-8 $(2.0 \mathrm{mg} / \mathrm{kg}$ ) and no retrieval trial before home cage return (squares), vehicle with a retrieval trial (diamonds) and TDZD-8 $(2.0 \mathrm{mg} / \mathrm{kg}$ ) with a retrieval trial (triangles) before home cage return. ${ }^{\#} P<0.05$ compared to control rats (circles). 


\section{Intermediate Learners}
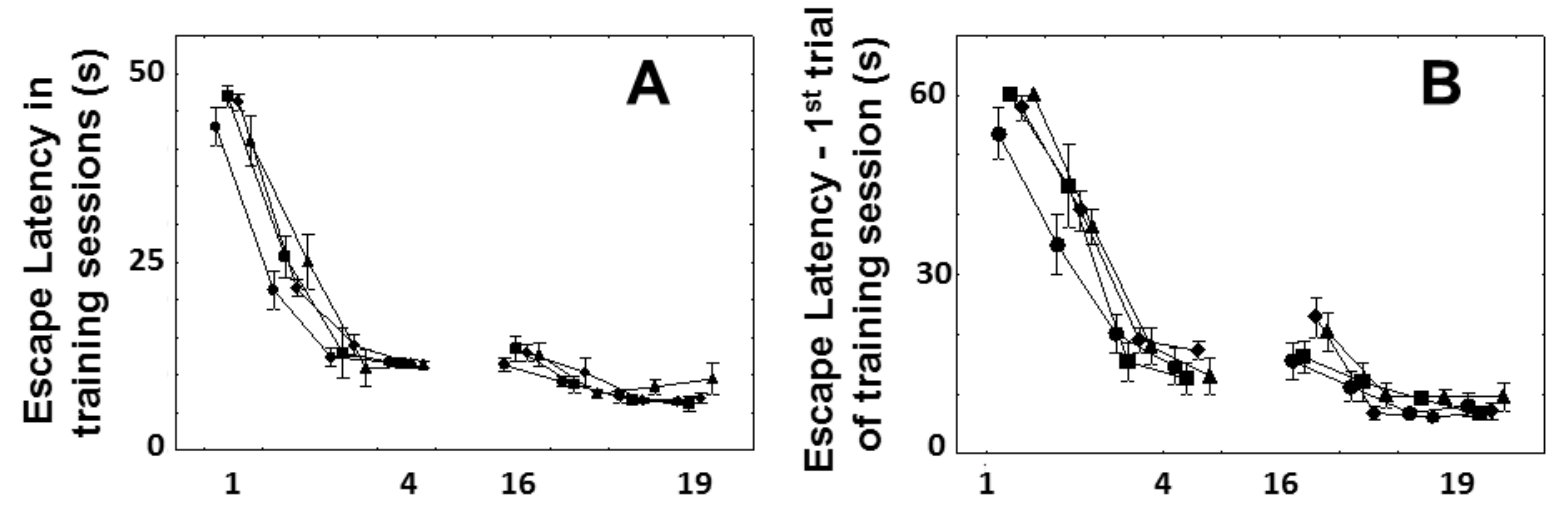

Protocol Days

Figure 4 - (A) Daily overall trial- and (B) first trial-swimming escape latencies (s, mean \pm sem) of intermediate learner rats in the Morris water maze on protocol days 1-4 and 16-19. Animals received i.p. on day 5: vehicle and no retrieval trial before home cage return (circles), TDZD-8 $(2.0 \mathrm{mg} / \mathrm{kg})$ and no retrieval trial before home cage return (squares), vehicle with a retrieval trial (diamonds) and TDZD-8 $(2.0 \mathrm{mg} / \mathrm{kg})$ with a retrieval trial (triangles) before home cage return.

\section{Inferior Learners}
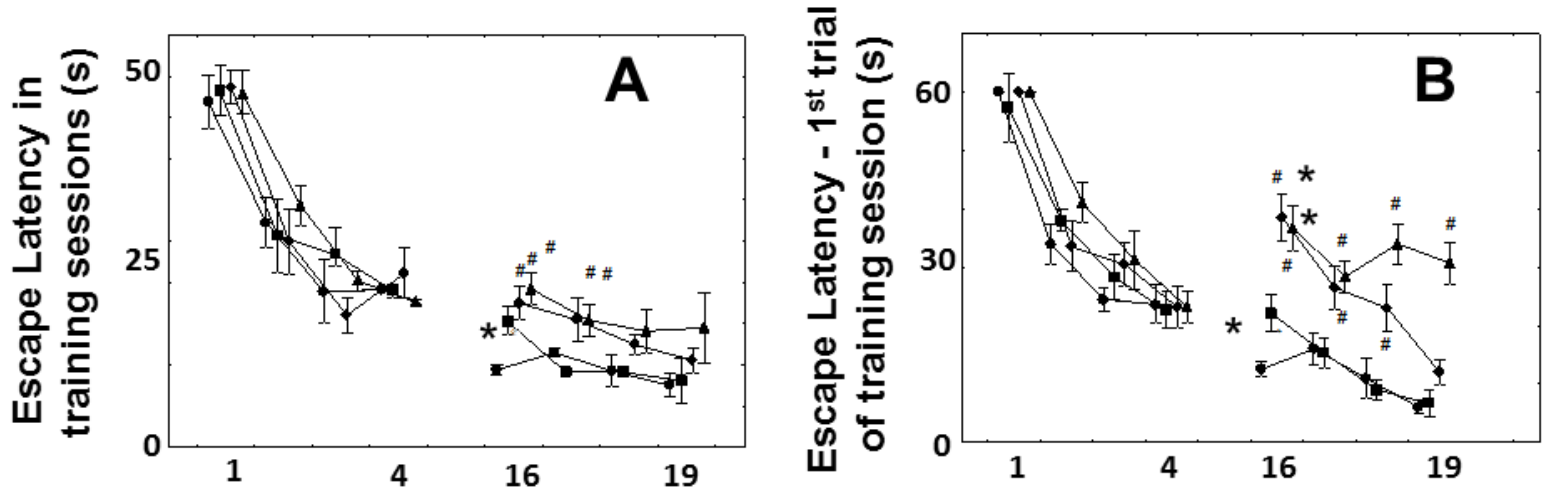

\section{Protocol Days}

Figure 5 - (A) Daily overall trial- (B) and first trial-swimming escape latencies (s, mean \pm sem) of inferior learner rats in the Morris water maze on protocol days 1-4 and 16-19. Animals received i.p. on day 5: vehicle and no retrieval trial before home cage return (circles), TDZD-8 $(2.0 \mathrm{mg} / \mathrm{kg})$ and no retrieval trial before home cage return (squares), vehicle with a retrieval trial (diamonds) and TDZD-8 $(2.0 \mathrm{mg} / \mathrm{kg}$ ) with a retrieval trial (triangles) before home cage return. ${ }^{\#} P<0.05$ relative to control rats (circles). ${ }^{*} P<0.05$ compared to day 4 latency. 


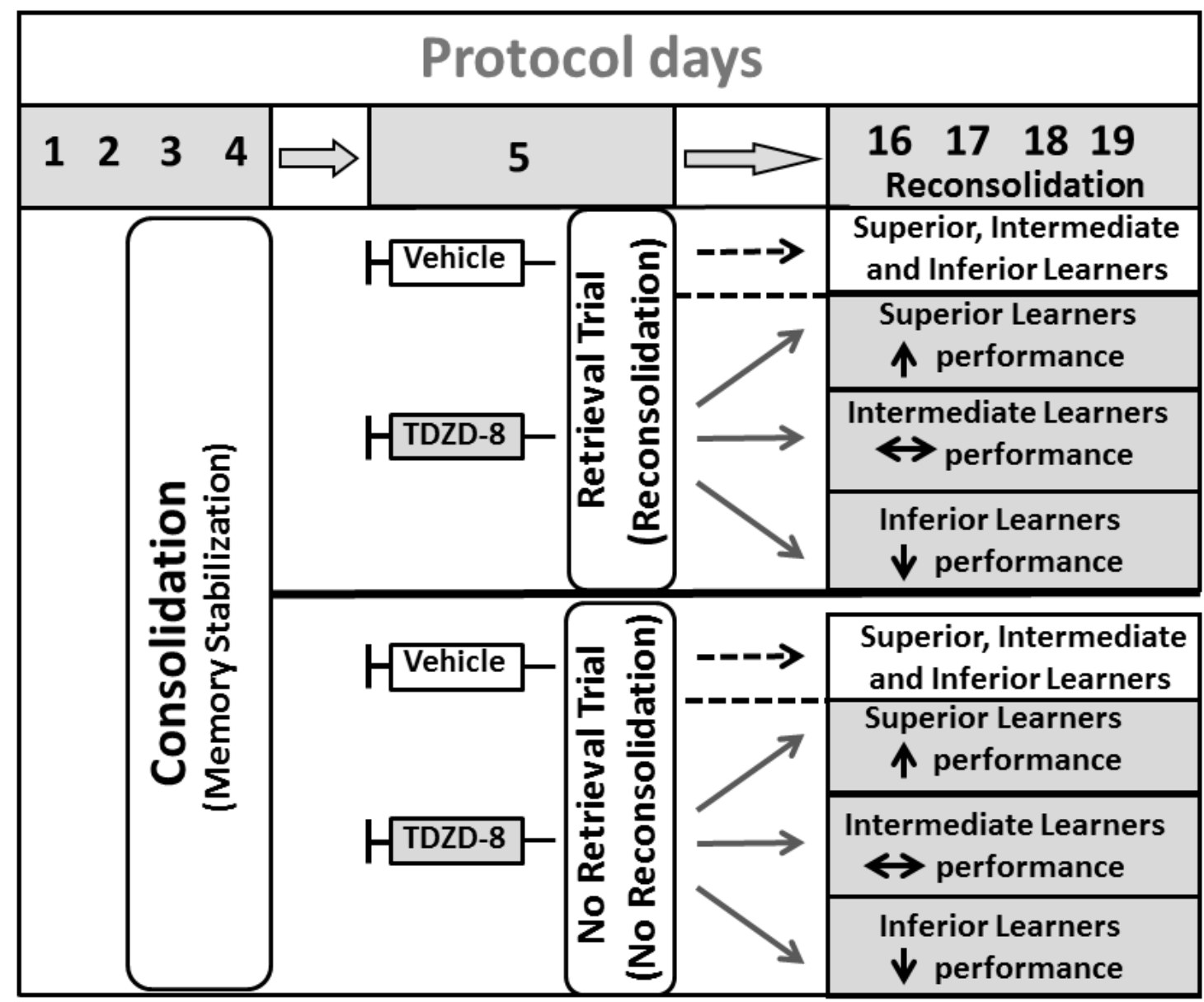

Figure 6 - Scheme summarizing the experimental results in superior, intermediate and inferior learner rats trained to spatial memory formation and its consolidation (protocol days 1-4) and after i.p. administration of vehicle or TDZD-8 (2.0 mg/kg) followed by a Morris water maze retrieval trial with reconsolidation of spatial memory or animal return to the home cage without retrieval trial on protocol day 5. Subsequent visuospatial performance outcomes during repeated learning protocol days 16-19 are shown as: an upwards arrow performance enhancement; downwards arrow - impairment; double horizontal arrow - no modification of visuospatial performance in the water maze. 